American Journal of Applied Sciences 6 (12): 2078-2084, 2009

ISSN 1546-9239

(C) 2009 Science Publications

\title{
Relationship between Nickel Exposure and the Level of Carcinoembryonic Antigen among Welders in an Automotive Plant
}

\author{
${ }^{1}$ Chiang Lee Juan, ${ }^{1}$ Shamsul Bahri Mohd Tamrin, ${ }^{1}$ Syazwan Aizat Ismail, ${ }^{1}$ Ridhuan Md Dan, \\ ${ }^{2}$ Mohd Roslan Sulaiman and ${ }^{1}$ Zailina Hashim \\ ${ }^{1}$ Department of Community Health, Faculty of Medicine and Health Sciences, \\ Universiti Putra Malaysia, 43400 Serdang, \\ Selangor, Malaysia \\ ${ }^{2}$ Department of Biomedical Sciences, Faculty of Medicine and Health Sciences, \\ Universiti Putra Malaysia, 43400 Serdang, \\ Selangor, Malaysia
}

\begin{abstract}
Background: Study on the effect of nickel exposure in the occupational setting and its association to carcinoembryonic antigen (CEA) had been studied before. Questions were raised whether the result from previous study would also show the same pattern of the urinary nickel concentration in this study. Objective: A cross-sectional study was conducted to determine the association between urine nickel concentration and CEA level among welders in automotive part workers in Malaysia. Methodology: There were 56 welders and 44 administrative workers were recruited in this study. Urine and blood samples were collected at the end of shift towards the end of workweek. CEA was assayed in serum using TECO Diagnostic ELISA Kit. Urinary nickel was determined by Graphite Furnace Atomic Absorption Spectrophotometer. Results: The mean carcinoembryonic antigen concentrations of the exposed group $\left(4.07 \pm 2.60 \mathrm{ng} \mathrm{mL}^{-1}\right)$ was significantly higher $(\mathrm{p}<0.001)$ than the control group $\left(1.99 \pm 0.97 \mathrm{ng} \mathrm{mL}^{-1}\right)$. Twenty seven percent of the exposed group showed values above the reference range. The mean urinary nickel level was also significantly higher $(\mathrm{p}<0.001)$ in the exposed group $\left(1.99 \pm 0.91 \mathrm{mg} \mathrm{L}^{-1}\right)$ than the control group. Result showed correlation between serum carcinoembryonic antigen concentration and urinary nickel concentration $(\mathrm{r}$ $=0.206$ ). . Conclusion: The significant elevation of urinary nickel levels in the welders compared with controls suggests that the welders were exposed to nickel fumes during welding. It is suggested that elevation of serum carcinoembryonic antigen was due to exposure to nickel during welding processes after controlling other confounding factors.
\end{abstract}

Key words: Urinary nickel, CEA, welders, automotive industries.

\section{INTRODUCTION}

Nickel (Ni) had been used widely in stainless steel industries throughout the world especially activities involved with welding. The chemical hazards of welding occur when fumes arise from stainless steel being welded. Welding fumes contain varying concentrations of potential toxic gases and metals such as manganese, copper and nickel. Although Nickel, chromium, arsenic and beryllium are human carcinogens, only nickel and chromium hexavalent appear to have significant concentrations in the welding environment ${ }^{[14]}$. Studies of nickel exposure were well documented when blood, tissues and in urine samples showed higher concentrations in occupation with direct nickel exposure ${ }^{[7,11,21-23]}$.

In occupational settings a major route of exposure is direct inhalation of nickel fumes and dust ${ }^{[15]}$. Approximately $30 \%$ of inhaled nickel reaches the lungs and $20 \%$ of inhaled nickel is absorbed into the circulation and $\mathrm{Ni}^{2+}$ has the ability to enhance DNA methylation. Through this process, tumor cells may form as a result of inactivated expression of tumor suppressor gene ${ }^{[6]}$, thus increasing the

Corresponding Author: Syazwan Aizat Ismail, Department of Community Health, Faculty of Medicine and Health Sciences, University Putra Malaysia, 43400 Serdang, Selangor, Malaysia Tel: +603-89472358 Fax: +603-89472395 
Carcinoembryonic Antigen (CEA) level in the blood. With the abnormal elevation of CEA, we are able to screen and diagnose tumors derived from nickel exposure. Analyses of the relationship between serum CEA level and urine nickel concentration are appropriate for the appraisal of long term inhalation of $\mathrm{Ni}$ compounds. Therefore, the main purpose of this study was to determine the association between serum CEA and urinary nickel in welders.

\section{MATERIALS AND METHODS}

Study design and location: A cross sectional study design was conducted in a metal based automotive parts manufacturing plant with welding and stamping activities. The plant had 700 employees working in two shifts. Of the 700 workers, $43 \%$ were welders. Preliminary questionnaires were distributed to select and control confounding variables such as smoking, alcohol consumption, medical and employment history. Of the 700 workers only 56 welders were selected as the exposed group while 44 workers from administrative department selected as the control group. Consent from respondents was obtained prior to the interview. Sample size calculation was used to determine adequacy as described by Rubinson and Neutens ${ }^{[24]}$. The ethical committee of Faculty of Medicine and Health Sciences, University Putra Malaysia had given ethical clearance to this study.

Questionnaire: Detailed questionnaires comprised several sections which include questions regarding demographic information (age, marital status and annual income), occupational information (work duration and number of years of employment as a welder), smoking activities (daily number of cigarettes smoked and years of smoking) and information on the medical history of the respondents.

Sampling and analyses of urinary nickel: Urine was collected into a $50 \mathrm{~mL}$ acid-washed (50\% nitric acid) polyethylene container at the end of an $8 \mathrm{~h}$ shift on Fridays. All the samples were analyzed using the methods described by Sunderman et al. ${ }^{[26]}$ and Nixon et al. ${ }^{[20]}$. All urine analysis of Nickel was performed by Graphite Furnace Atomic Absorption Spectophotometry with Zeeman background correction (Hitachi Z-5700) in Industrial Hygiene laboratory, University Kebangsaan Malaysia (UKM) Medical Center.

Sampling and analyses of CEA: Blood $(5 \mathrm{~mL})$ was collected from each respondent by a qualified nurse. The serum was analysed for CEA level with CEA
ELISA test kit. Absorbance was measured using spectrophotometry at $450 \mathrm{~nm}^{[27]}$. The blood specimens were centrifuged in a desiccated centrifuge with hermetically sealed trunnion cups.

\section{RESULTS}

Demographic information: Fifty-six Malay male welders (exposed group) and a control group consisted of 44 Malay males from the stamping operations $(n=34)$ and office workers $(n=10)$ were examined for this study. Face-to-face interviews were conducted with all the 100 respondents to obtain their demographic information.

Table 1 shows the comparison of demographic data between the exposed and control group. Statistical analysis showed no significant difference in the level of education and number of cigarettes smoked per day between the groups $(p>0.05)$. However, there was significant difference in age, marital status, basic income, duration of work and smoking years between the groups $(\mathrm{p}<0.05)$. Each of the categorical of income, duration of working and smoking years was divided into categories.

Distribution of urinary nickel and serum CEA: Table 2 shows that the mean urinary nickel concentration was higher $\left(1.99 \mu \mathrm{g} \mathrm{L}^{-1}\right)$ in the exposed group than the control group $\left(1.28 \mu \mathrm{g} \mathrm{L}^{-1}\right)$. Using the 95th percentile of the control group as the reference limit, $10.7 \%$ of the exposed group was higher than the reference limit. Mann-Whitney U test showed a significantly higher urinary nickel concentration $(Z=-4.160, p<0.001)$ in the exposed group compared with the control group.

Result showed that the mean of CEA concentration was less than standard level $\left(5.0 \mathrm{ng} \mathrm{mL}^{-1}\right)$ but using the 95th percentile of CEA concentrations in the control group as the upper reference limit, $53.6 \%$ of the exposed group was above the reference limit. A total of $35.7 \%$ of the exposed group had CEA concentrations of less than $2.5 \mathrm{ng} \mathrm{mL}^{-1}$, while $26.8 \%$ of the exposed group had CEA concentrations above $5 \mathrm{ng} \mathrm{mL}^{-1}$. MannWhitney $U$ test showed a higher CEA concentration in expose group compared to control group $(Z=-4.736$, $\mathrm{p}<0.001)$.

Relationship between serum CEA with U-Ni and selected factors: There was a significant correlation between CEA with U-Ni concentrations and duration of welding $(\mathrm{p}<0.05)$, but no correlation was found with the number of cigarettes smoked. There was an inverse association between CEA level and age (Table 3). 
Am. J. Applied Sci., 6 (12): 2078-2084, 2009

Table 1: Demographic data of the respondents $(\mathrm{N}=100)$

\begin{tabular}{|c|c|c|c|}
\hline Demographics & $\begin{array}{l}\text { Exposed } \\
\mathrm{N}=56(\%)\end{array}$ & $\begin{array}{l}\text { Control } \\
\mathrm{N}=44(\%)\end{array}$ & $\begin{array}{l}\mathrm{x}^{2} \text { value } \\
\text { (p-value) }\end{array}$ \\
\hline \multicolumn{4}{|l|}{ Age (years) } \\
\hline $19-24$ & $46(82.1)$ & $20(45.5)$ & \multirow{3}{*}{$\begin{array}{l}15.26 \\
(<0.001)^{* *}\end{array}$} \\
\hline $25-30$ & $9(16.8)$ & $19(43.2)$ & \\
\hline $31-35$ & $1(1.8)$ & $5(11.4)$ & \\
\hline \multicolumn{4}{|l|}{ Marital status } \\
\hline Single & $50(89.3)$ & $26(59.1)$ & \multirow{2}{*}{$\begin{array}{c}12.316 \\
(<0.001)^{* *}\end{array}$} \\
\hline Married & $6(10.7)$ & $18(40.9)$ & \\
\hline \multicolumn{4}{|l|}{ Education } \\
\hline UPSR & $1(1.8)$ & $0(0)$ & 3.62 \\
\hline SRP/PMR & $10(17.9)$ & $10(22.7)$ & \multirow{3}{*}{-0.36} \\
\hline SPM/STPM & $43(76.8)$ & $29(65.9)$ & \\
\hline College/University & $2(3.6)$ & $5(11.4)$ & \\
\hline \multicolumn{4}{|l|}{ Basic income (RM) } \\
\hline$<600$ & $29(51.8)$ & $8(18.2)$ & \multirow{3}{*}{$\begin{array}{l}13.561 \\
(0.001)^{* *}\end{array}$} \\
\hline $600-700$ & $15(26.8)$ & $14(31.8)$ & \\
\hline$>00$ & $12(21.4)$ & $12(50.0)$ & \\
\hline \multicolumn{4}{|c|}{ Duration of working (years) } \\
\hline$<2.5$ & $43(76.8)$ & $50(50)$ & \multirow{2}{*}{$\begin{array}{l}7.771 \\
(0.005)^{*}\end{array}$} \\
\hline$>2.5$ & $13(23.2)$ & $50(50)$ & \\
\hline \multicolumn{4}{|c|}{ Number of cigarette smoked per day } \\
\hline$<10$ & $35(62.5)$ & $27(61.4)$ & 0.014 \\
\hline$>10$ & $21(37.5)$ & $17(38.6)$ & -0.907 \\
\hline \multicolumn{4}{|c|}{ Duration of smoking (years) } \\
\hline$<5$ & $30(64.3)$ & $19(43.2)$ & 4.434 \\
\hline$>5$ & $26(35.7)$ & $25(56.8)$ & $(0.035)^{*}$ \\
\hline
\end{tabular}

Table 2: Distribution of urinary-nickel and CEA concentrations of exposed and control group

\begin{tabular}{|c|c|c|c|c|}
\hline \multirow[b]{2}{*}{ Statistic } & \multicolumn{2}{|c|}{ U-Nickel Concentration } & \multicolumn{2}{|c|}{ Serum CEA Concentration } \\
\hline & Exposed $(\mathrm{N}=56)$ & Control $(\mathrm{N}=44)$ & Exposed $(\mathrm{N}=56)$ & Control $(\mathrm{N}=44)$ \\
\hline Mean ( \pm SD $)$ & $1.99(0.91)$ & $1.28(1.05)$ & $4.07(2.60)$ & $1.99(0.97)$ \\
\hline Median (Inter quartile range) & $1.69(0.71-4.00)$ & $1.09(0.09-5.52)$ & $3.67(1.20-15.22)$ & $1.92(0.43-4.97)$ \\
\hline 95th Percentile & 3.85 & 3.58 & 8.96 & 3.43 \\
\hline
\end{tabular}

Table 3: Correlation between CEA concentrations with selected variables

\begin{tabular}{lcc}
\hline \multicolumn{1}{c}{ variables } & CEA concentration \\
& ---------- \\
Parameters & r-value & p-value \\
\hline U-Ni concentrations & 0.206 & $0.040^{*}$ \\
Age & -0.256 & $0.010^{*}$ \\
Duration of welding & 0.365 & $<0.001^{* * *}$ \\
Number of cigarette smoked per day & -0.002 & 0.981 \\
\hline ***: p-value is significant at $\mathrm{p}<0.001 ; *: \mathrm{p}$-value is significant at \\
$\mathrm{p}<0.05$
\end{tabular}

\section{DISCUSSION}

Distribution of urinary nickel concentration: Urinary Nickel (U-Ni) concentrations in the exposed group in our study were compared with the urinary nickel concentrations reported in other studies ${ }^{[1,7,11,21-23]}$. From Table 4, it can be seen that all the previous studies reported higher U-Ni c oncentrations than our study. The nickel electroplating workers in the study by Sunderman et al. ${ }^{[26]}$ had the highest average U-Ni concentrations $\left(27.1 \mu \mathrm{g} \mathrm{L}^{-1}\right)$ while a study in Finland ${ }^{[11]}$ reported the lowest levels $\left(8.7 \mu \mathrm{g} \mathrm{L}^{-1}\right)$. The mean urinary nickel concentration of stainless steel welders in the Finland study ${ }^{[1]}$ was at least 5.8 times higher than in our study. When the respondents from previous studies were divided into 3 categories; nickel electroplating workers $^{[7,23]}$ stainless steel welders ${ }^{[1,11]}$ and high-Ni alloy welders ${ }^{[23]}$. The nickel electroplating workers had the highest U-Ni concentrations, followed by stainless steel welders and high-nickel alloy welders.

Factors such as the amount deposited and particle solubility, surface area and size will influence the behavior of nickel particles deposited in the respiratory tract and will probably account for the differences in retention and clearance via absorption. Based largely upon experimental data, it can be concluded that the more soluble the compound, the more readily it is absorbed from the lung into the bloodstream and excreted in the urine ${ }^{[19]}$. According to Oliveira et al. ${ }^{[21]}$, 
Am. J. Applied Sci., 6 (12): 2078-2084, 2009

Table 4: Comparison of U-Ni concentrations of exposed group in previous studies and present study

\begin{tabular}{|c|c|c|c|c|}
\hline Authors & Country & Occupation & Sample size & Mean $\left(\mu \mathrm{g} \mathrm{L}^{-1}\right)$ \\
\hline This study & Malaysia & Automotive parts welder & 56 & $1.99 \pm 0.9$ \\
\hline Oliveira et al..$^{[21]}$ & Brazil & Nickel electroplating worker & 10 & $20.6 \pm 18.1$ \\
\hline Angerer and Lehnert ${ }^{[1]}$ & Germany & Stainless steel welder & 103 & $18.5 \pm 28.5$ \\
\hline Sunderman et al. ${ }^{[26]}$ & United States & Nickel electroplating worker & 16 & $27.1 \pm 21.2$ \\
\hline Åkesson and Skerfving ${ }^{[28]}$ & Sweden & High-nickel alloy welder & 11 & $8.7 *$ \\
\hline Rahkonen et al. ${ }^{[29]}$ & Finland & Stainless steel welder & 7 & $11.5 \pm 1.6$ \\
\hline
\end{tabular}

*: Standard deviation was not stated

the nickel electroplating workers were exposed to soluble nickel compounds, while the stainless steel welders and high-nickel alloy welders were exposed to extremely low solubility of nickel aerosol ${ }^{[23]}$. This phenomenon explains why the Nickel electroplating workers recorded higher U-Ni concentrations than stainless steel welders and high-Ni alloy welders.

Carcinoembryonic Antigen (CEA): For exposed group, the CEA concentrations ranged between 1.20 and $15.22 \mathrm{ng} \mathrm{mL}^{-1}$. The comparison of CEA concentrations for the exposed group with other studies could not be made as there has not been any study of CEA on welders or subjects exposed to nickel. The clinical value of CEA was evaluated prospectively in 118 patients with small cell lung cancer. Seventy percent of patients had levels less than $5.0 \mathrm{ng} \mathrm{mL}^{-1}$ and only $19 \%$ had levels greater than $20.0 \mathrm{ng} \mathrm{mL}^{-1[16]}$. Carcinoembryonic antigen was measured in samples of serum coming from 105 non-small cell lung cancer patients. The median and inter quartile range were 3.0 and $7.0 \mathrm{ng} \mathrm{mL}^{-1}$. CEA was higher than $5.0 \mathrm{ng} \mathrm{mL}^{-1}$ in $38 \%$ of patients ${ }^{[17]}$. For this study, a total of $15(26.8 \%)$ welders had CEA concentrations above $5 \mathrm{ng} \mathrm{mL}^{-1}$. Carcinoembryonic antigen concentrations of 30 welders $(53.6 \%)$ were higher than the upper reference limit of this study.

Concentrations of $2.5-5.0 \mathrm{ng} \mathrm{mL} \mathrm{m}^{-1}$ are commonly considered as cut-off points for distinguishing normal from abnormal levels of serum $\mathrm{CEA}^{[10]}$. Values more than $2.5 \mathrm{ng} \mathrm{mL} \mathrm{mL}^{-1}$ may be found in associations with cancers $^{[18]}$. Similarly, raised serum CEA levels could be detected in cigarette smokers, which were why the respondents of this study consisted of smokers for both exposed and the control group, to eliminate the confounding effect of tobacco smoking on serum CEA levels.

In this study, there were several reasons for employing serum CEA among the numerous tumor markers for lung cancer monitoring. In an ideal tumor marker should increase pathologically in the presence of a neoplasm (high sensitivity) and not increase in the absence of neoplasm (high specificity). It should also possess constant serum levels with no major fluctuations and easy and inexpensive ${ }^{[8]}$. Serum CEA has the mentioned characteristics. Serum CEA has been reported for its high sensitivity in several studies. In a prospective study that aimed to assess the diagnostic value of serum CEA, cytokeratin 19 fragment marker (CYFRA 21-1) and Neuron-Specific Enolase (NSE) in the differentiation of malignant from benign solitary pulmonary lesions, serum CEA recorded the highest sensitivity (27.2\%) and accuracy $(40.4 \%)$ when used as a tumor marker alone ${ }^{[25]}$. In another study ${ }^{[12]}$, the highest sensitivity $(85.3 \%)$ was found in serum CEA. The diagnostic accuracy was $74 \%$ for serum CEA, which was higher than NSE $(66 \%)$ and CA-50 antigen $(62 \%)^{[4]}$.

The standard diagnostic procedures in the evaluation of suspected lung cancer include sputum cytology, bronchoscopy and transthoracic needle aspiration. These procedures are complex, expensive and time-consuming in clinical practice ${ }^{[4,5]}$. However, tumour marker analysis has the advantage of simplicity in sampling technique (only blood sample is required), which makes it applicable to the respondents. Furthermore, the serum test is inexpensive ${ }^{[5]}$ and proves to be useful as a complementary tool if standard diagnostic procedures are not applicable to patients ${ }^{[4]}$. In patients affected by lung cancer, abnormally elevated values of the marker can be found in $30-70 \%$ of the samples $^{[5]}$.

Relationship between CEA and urinary nickel concentrations: Spearman's rho correlation coefficient demonstrated a significant correlation $(r=0.206 ; p=0.040)$ between urinary Nickel and CEA concentrations. As mentioned earlier, there has not been any study looking at the relationship between these two parameters. This finding facilitates appraisal of the correlation between lung cancer and occupational exposure to nickel.

Nickel forms $\mathrm{Ni}^{2+}$ ion in body fluids and has the ability to enhance DNA methylation specifically in regions bordering heterochromatin. Through this process, many tumors can arise as a result of inactivated expression of a tumor suppressor gene by hypermethylation of their promoter region ${ }^{[6]}$. Thus, an 
increased level of urinary Nickel can accelerate the DNA methylation and produce more tumors in the body. As a result of this activity, tumors in the blood circulation can release more $\mathrm{CEA}^{[18]}$.

It should be noted that inorganic compounds of arsenic, beryllium, cadmium and chromium might be present in welding fumes ${ }^{[14]}$. However, only nickel and chromium appear in significant concentrations in the welding environment ${ }^{[14]}$. These agents may interfere with each other to produce synergistic or perhaps antagonistic effects. Pretreatment with nickel has earlier been shown to protect against cadmium intoxication in experiments ${ }^{[13]}$. No concrete information seems to be available for the evaluation of synergism or antagonisms of nickel and other carcinogens present in welding fumes. According to Furst ${ }^{[9]}$, an infinite number of possibilities exist for studies on how Nickel compounds are involved in the cancer process.

Nevertheless, this study has shown that both the urinary nickel concentrations and CEA concentrations of exposed group were significantly higher than the control group. However, no significant relationship ( $>0.05)$ between urinary chromium and CEA concentrations was observed. As only nickel and chromium appear in significant concentrations in the welding environment ${ }^{[14]}$, this non-correlation indicates that the raised Nickel levels in urine of the welders appear to be the contributory factor to the elevated CEA levels in the welders. Hence nickel compounds pose a higher risk of CEA elevation than chromium in the body.

\section{Relationship of CEA with other variables:}

Duration of welding: A significant correlation $(r=0.365$; $\mathrm{p}<0.001)$ was observed between CEA concentrations and duration of welding. Duration of exposure to low dosages of carcinogens is a critical factor ${ }^{[2]}$. Nickel, chromium and other carcinogenic elements in welding fumes can induce carcinogenic effects on welders and are capable of causing elevated CEA levels in serum. Duration of welding should represent the cumulative exposure to carcinogenic elements in the welding fumes. It should be noted that Spearman's rho correlation coefficient demonstrated no correlation between CEA concentrations and duration of work $(\mathrm{r}=-0.142 ; \mathrm{p}=0.160)$. This non-correlation indicated that the CEA concentration was independent of duration of work at the study location, but correlated with the number of years of exposure to welding which shows chronic exposure and long term body burden. About $20 \%$ of the welders had worked as welders at different places before being employed at this study location.
Age: Spearman's rho correlation coefficients showed an inverse relationship $(r=-0.256 ; p=0.01)$ between CEA and age. The inverse relationship was unexpected and may be due to the large number of young workers in this study. In a review of CEA by Gold and Goldenberg ${ }^{[10]}$, who reported raised CEA levels in older subjects compared to younger individuals. Nevertheless, the influence of sex is more important than that the age in CEA determination ${ }^{[3]}$. This finding is supported by the conclusion that the influence of age in CEA determination is of minor importance.

Cigarettes smoking: The study found a non significant correlation between CEA concentrations and number of cigarettes smoked per day. This finding contradicts the results of finding by Gold and Goldenberg ${ }^{[10]}$ who found that CEA was raised in smokers. Since the homogeneity of smoking was control in both groups, the increase of serum CEA level in the exposed group may be caused by exposure to nickel fumes.

\section{CONCLUSION}

Our study had shown a relationship between Nickel exposure and the level of serum CEA. Although it is no specific, it may serve as a useful biomarker for cancer screening associated with chemical carcinogen exposure. The detection of this marker may prove useful for early intervention and prevention activities. For example, in persons with highly elevated serum CEA, further diagnosis testing is recommended. Therefore, more studies of CEA levels should be conducted in the future to evaluate the potential role of determination of CEA level among the high-risk groups such as welders who are exposed to hazardous fumes.

\section{ACKNOWLEDGMENT}

The researcher would like to thank Mr. Azman Abdul Aziz, Prof. Dr Jamal Hisham Hashim, Mr. Ariffin Omar, Ms. Safarina and Ms. Salina. Special thanks to the staff from Industrial Hygiene laboratory, UKM Medical Center. Special thanks also for all staff from Department of Community Health, Faculty of Medicine and Health Sciences, UPM.

\section{REFERENCES}

1. Angerer, J. and G. Lehnert, 1990. Occupational chronic exposure to metals II. Nickel exposure of stainless steel welders-biological monitoring. Int. Arch. Occup. Environ. Health, 62: 7-10. PMID: 2295525 
2. Armstrong, R.W., 1980. Environmental Influences in Cancer Aetiology. In: Environmental Medicine, Howe, G.M. and J.A. Loraine (Eds.), 2nd Edn., William Heinemann Medical Books Ltd., London, pp: 170-189.

3. Beaudonnet, A., G. Gounon, J. Pichot and M.C. Revenant, 1981. Sex and age-related influences on CEA in blood. Clin. Chem., 27: 771.

4. Bergman, B., F.T. Brezicka, C.P. Engström and S. Larsson, 1993. Clinical usefulness of serum assays of neuron-specific enolase, carcinoembryonic antigen and CA-50 antigen in the diagnosis of lung cancer. Eur. J. Cancer, 29A: 198-202. PMID: 8380696

5. Buccheri, G., 1999. Tumor Markers: Clinical Meaning and Use. In: Lung Tumors, Soussi, T. (Ed.). Marcel Dekker Inc., New York, pp: 436-452.

6. Costa, M., J.E. Sutherland, W. Peng, K. Salnikow, L. Broday and T. Kluz, 2001. Molecular biology of nickel carcinogenesis. Mol Cell Biochem., 222: 205-11. PMID: 11678603

7. David Fishwick, L. Bradshaw, T. Slater, A. Curran and N. Pearce, 2004. Respiratory symptoms and lung function change in welders: Are they associated with workplace exposures? N. Z. Med. J117: U872. PMID: 15133522

8. Ferrigno, D., G. Buccheri and A. Biggi, 1994. Serum tumour markers in lung cancer: history, biology and clinical applications. Eur. Respir. J., 7: 186-197. PMID: 8143820

9. Furst, A., 1984. Mechanism of Action of Nickel as a Carcinogen: Needed Information. In: Nickel in the Environment, Sunderman Jr., F.W., A. Aitio, A. Berlin, L. Bishop, E. Buringh and Davis W. Lyon (Eds.). International Agency for Research on Cancer, pp: 245-252.

10. Gold, P. and N.A. Goldenberg, 1997. The Carcinoembryonic Antigen (CEA): Past, present and future. McGill J. Med., 3: 46-66. http://www.medicine.mcgill.ca/mjm/v03n01/cea.ht $\mathrm{ml}$

11. Janicka, K. and M. Cempel, 2003. Effect of nickel (II) chloride oral exposure on urinary nickel excretion and some other elements. Polish J. Environ. $\quad$ Stud., 12: 563-566. http://www.pjoes.com/pdf/12.5/563-566.pdf

12. Kaeva, B., T. Stefanovski, B. Polenakovic, M. Demireva, E. Naumovski and S. Stojkovski, 1997. The tumor markers CEA, MCA and CA 19-9 at pleural effusions and primary tumor of the lung. Lung Cancer, 18: 221-221. DOI: 10.1016/S01695002(97)80239-5
13. Khandelwal, S. and S.K. Tandon, 1984. Effect of Cadmium Pretreatment on Nickel Toxicity. In: Nickel in the Environment, Sunderman Jr., F.W., A. Aitio, A. Berlin, L. Bishop, E. Buringh and W. Davis (Eds.). International Agency for Research on Cancer, Lyon, pp: 293-300. http://www9.euskadi.net/sanidad/osteba/datos/d_02 -03_marcadores_tumorales.pdf.

14. Langård, S. and R.M. Stern, 1984. Nickel in Welding Fumes-a Cancer Hazard to Welders In: Nickel in the Environment, Sunderman Jr., F.W., A. Aitio, A. Berlin, L. Bishop, E. Buringh and W. Davis (Eds.). International Agency for Research on Cancer, Lyon, pp: 95-103. http://www9.euskadi.net/sanidad/osteba/datos/d_02 -03_marcadores_tumorales.pdf

15. Lipmann, M., 1999. Environmental Toxicants. 2nd Edn., John Wiley and Sons, New York, pp: 20-35.

16. Michetti, G., M. Bamberga, C. Pugliese, M.O. Belometti, P. Arnone and A. Minio, 1995. Significancer of the dosage of plasma CEA in small cell carcinoma. Lung Cancer, 12: 135-135. DOI: 10.1016/01695002(95)96364-2

17. Moro, D., D. Villemain, J.P. Vuillez, C.A. Delord and C. Brambilla, 1995. CEA, CYFRA21-1 and SCC in non-small cell lung cancer. Lung Cancer, 13: 169-76. PMID: 8581396

18. National Institute of Health, 2001. National Institute of Health CEA: Its role as a marker in the management of cancer. http://text.nlm.nih.gov/nih/cdc/www/28txt.html

19. Nickel Producers Environmental Research Association, 2002. Nickel Producers Environmental Research Association (Nipera) Pharmacokinetics of nickel exposure. http://www.nipera.org/

20. Nixon, D.E., T.P. Moyer, D.P. Squillace and J.T. McCarthy, 1989. Determination of serum nickel by graphite furnace atomic absorption spectrometry with Zeeman-effect background correction: Values in a normal population and a population undergoing dialysis. Analyst, 114: 1671-1674. PMID: 2633657

21. Oliveira, J.P., M.E. de Siqueira and C.S. da Silvam 2000. Urinary nickel as bioindicator of workers' Ni exposure in a galvanizing plant in Brazil. Int. Arch. Occup. Environ. Health, 73: 65-68. PMID: 10672494

22. Pelclova, D., 2008. Occupational asthma in the chemical industry. Clin. Toxicol., 46: 351. http://md1.csa.com/partners/viewrecord.php?reque ster $=$ gs\&collection $=$ ENV\&recid $=8342506$ 
23. Kalahasthi, R.B., R.H.R. Rao, R.B.K. Murthy and M.K. Kumar, 2008. Effect of nickel exposure on serum amylase activity in nickel-plating workers. Toxicol. Environ. Chem., 90: 393-400. DOI: 10.1080/02772240701543625

24. Rubinson, L. and J.J. Neutens, 1987. Survey Sampling: Sample Size. Research Techniques for Health Sciences. Macmillan Publishing Company, New York.

25. Seemann, M.D., T. Beinert, F. Heinrich and U. Fink, 1999. An evaluation of tumor markers, CEA, CYFRA 21-1 and NSE in the differentiation of malignant from benign solitary pulmonary lesions. Lung Cancer, 26: 149-155.

26. Sunderman Jr., F.W., S.M. Hopfer and M.C. Crisostomo, 1988. Nickel analysis by electrothermal atomic absorption spectrometry. Methods Enzymol., 158: 382-91. PMID: 3374390
27. Teco diagnostics Limited, 2001. Teco diagnostics Limited CEA ELISA test kit procedure. http://www.tecodiag.com/index.php?option=com_p roducts $\&$ task $=9 \&$ Itemid $=37$

28. Akesson, B. and S. Skerfving, 1985. Exposure in welding of high nickel alloy. Int. Arch. Occup. Environ. Health, 56: 111-117. PMID: 4055066

29. Rahkonen, E., M.L. Junttila, P.L. Kalliomäki, M. Olkinouora, M. Koponen and K. Kalliomäki, 1983. Evaluation of biological monitoring among stainless steel welders. Int. Arch. Occup. Environ. Health, 52: 243-255. DOI: 10.1007/BF00526523 